\title{
Anthropology and mental health care
}

\author{
R. E. Drake, Guest Editor*
}

Whitley (2015) summarises the global movement for mental health (Lancet Global Mental Health Group, 2008): its history and positive contributions as well as criticisms related to its failure to account for culture and context, with the attendant risks of pragmatic failure and eliciting fears of top-down imperialism. He points out that conceptualisations of psychological suffering and healing are inherently diverse and complex in all countries and in multi-cultural societies. In many locations, Western biomedical models of disease do not make sense to everyday people and to indigenous healers.

Carpenter-Song (2015) reminds us that overlooking culture and context is common in the USA also, and that overreliance on a narrow pharmacological paradigm has degraded the quality of mental health care. Many people get medications rather than the psychosocial supports they seek (Honberg et al. 2011). The problems are more severe for minorities and immigrants, who suffer gross health inequities, do not embrace the biomedical paradigm of mental illness, do not trust the health care system and often prefer cultural models of suffering and recovery (U.S. Department of Health and Human Services, 2001).

Both of these essays raise the fundamental problem of conceptualising and treating social, environmental and psychological stress as medical diseases. Even Vikram Patel, one of the major architects of the global mental health movement, acknowledges a major credibility gap between the small group of Western epidemiologists and biomedical researchers who have created the movement and the overwhelming majority of the world's population who believe in other models of suffering and caring (Patel, 2014). People simply do not accept that much of psychological suffering reflects biomedical diseases rather than normal psycho-social processes. The biomedical model that construes psychological suffering as disease states in need of medication does not fit their personal experiences, cultural values, religious beliefs and life philosophies. Like many American researchers (Frances, 2013), they find the everexpanding and arcane nomenclature of the American

\footnotetext{
* Address for correspondence: R. E. Drake, Dartmouth Psychiatric Research Center, Lebanon, New Hampshire, USA.

(Email: Robert.E.Drake@dartmouth.edu)
}

Psychiatric Association's Diagnostic and Statistical Manuals increasingly bizarre and incomprehensible.

In addition to poor fit, ignoring culture, challenging personal experience, arcane classification and the perception of renewed imperialism, global mental health devalues the effects of violence, poverty and inequality. Many people in all countries lack access to power, education, healthy food, money, jobs and basic services. They experience stress and cumulative adversity throughout their lives, even worse in the areas of civil war and terrorism. Violence towards women and minority groups, stigma, low expectations, hopelessness, governmental corruption, infant mortality, infectious disease and other ills affect their daily lives. For people who are poor and disenfranchised, psychological distress represents just one surface manifestation of their suffering.

Consider, for example, the indigenous people of many countries, including the USA. They have experienced centuries of historical trauma, enslavement, genocide, forced relocation and religious conversion, lack of full citizenship, minimal economic and employment opportunities and severe stigma (Heart et al. 2011). Cultural tensions, substance abuse, violence against women, hopelessness and high suicide rates are almost inevitable consequences of historical process. Or consider post-genocide and post-civil war societies. In countries like Rwanda and Kosovo, where the majority of the population has experienced serious trauma, the people embrace societal healing processes and resist applying psychiatric diagnoses to all those who have been affected (Adjukovic, 2005).

Similarly, consider the often-overlooked problem of violence against women. Across the world, one in three women experience intimate partner violence, often condoned by the culture of male patriarchy; and other women experience forced early marriage, honour killing, rape, female genital mutilation and other abuses (Ellsburg et al. 2014). Many women lack access to education, skills, jobs, money, power and basic resources. While researchers and health leaders in wealthy countries emphasise helping women and girls who are abused (Garcia-Moreno et al. 2014), leaders in poor countries recognise that these problems are endemic and require political, social, cultural, educational, economic and community-based remedies (Michau et al. 2014). A narrow biomedical approach 
to diagnosis and treatment - sedating the population with antidepressants and pain medications - would be grossly inadequate.

If the common determinants of mental problems are poverty, gender inequality, social exclusion and conflict (Patel, 2015), how should we, as mental health professionals, address the endemic social, economic, political and cultural problems that produce psychological stress and mental symptoms? Anthropologists remind us that we need to work with existing institutions, cultural beliefs and social processes rather than attempt to substitute Western biomedicine as a 'more scientific' model (Hopper, 2013). We also need to recognise the strengths of traditional beliefs and cultures, and listen to local stakeholders in building service systems (Drake et al. 2014). Recognising the complexity of culture and the structural antecedents of psychological stress should not paralyse efforts to reduce suffering. The challenge is to work collaboratively, in partnership with communities, towards pragmatic goals. For example, Native Americans are willing to adopt some evidence-based interventions when they are combined with trusted, culture-bound interventions (Walker \& Bigelow, 2011). We must also embrace the need for advocacy to address social injustice as a mental health intervention (Heart et al. 2011; Patel, 2015). Finally, we should all value the anthropologists' insights regarding mental health care but also insist that they offer solutions as well as criticisms (Whitley, 2014).

\section{Acknowledgements}

Thanks to Drs. Robert Whitley and Elizabeth Carpenter-Song for comments.

\section{Financial Support}

This research received no specific grant from any funding agency, commercial or not-for-profit sectors.

\section{Conflict of Interest}

None

\section{References}

Adjukovic D (2005). Social reconstruction of a local community after massive traumatization. In Promoting the Psychosocial Well Being of Children Follwing War and
Terrorism (ed. JJ Friedman and A Mikus-Kos), pp. 3-9. IOS Press: Washington, DC.

Carpenter-Song E (2015). Putting meaning into medicine: why context matters in American psychiatry. Epidemiology and Psychiatric Sciences, this issue.

Drake RE, Binagwaho A, Martell HC, Mulley AG (2014). New paradigms for behavioral and mental health. British Medical Journal 349, 7086.

Ellsburg M, Arango DJ, Morton M, Gennari F, Kiplesund S, Contreras M, Wattsw C (2014). Prevention of violence against women and girls: what does the evidence say? Lancet doi: http://dx.doi.org/10.1016/S0140-6736(14)61703-7

Frances A (2013). Saving Normal: An Insider's Revolt Against Out-of-control Psychiatric Diagnosis, DAM-V, Big Pharma, and the Medicalization of Ordinary Life. Harper Collins Publisher: New York.

Garcia-Moreno C, Hegarty K, d'Olivera AFL, Koziol-McLain J, Colombini M, Feder G (2014). The health-systems response to violence against women. Lancet doi: http://dx.doi.org/10.1016/S0140-6736(14)61837-7

Heart MY, Chase J, Elkins J, Altschul DB (2011). Historical trauma among indigenous peoples of the Americas: concepts, research, and clinical considerations. Journal of Psychoactive Drugs 43, 282-290.

Honberg R, Diehl S, Kimball A, Gruttadaro D, Fitzpatrick M (2011). State Mental Health Cuts: A National Crisis. National Alliance on Mental Illness.

Hopper K (2013). The murky middle ground - when ethnographers engage public health. Social Science and Medicine 99, 201-204.

Lancet Global Mental Health Group (2008). A movement for global mental health is launched. Lancet 372, 1274.

Michau L, Horn J, Bank A, Dutt M, Zimmerman C (2014). Prevention of violence against women and girls: lessons from practice. Lancet doi: http://dx.doi.org/10.1016/ S0140-6736(14)61797-9

Patel V (2014). Classification of mental disorders: a global mental health perspective. Lancet 383, 1433-1435.

Patel V (2015). Addressing social injustice: a key public mental health strategy. World Psychiatry 14, 43-44.

U.S. Department of Health and Human Services (2001). Mental Health: Culture, Race, and Ethnicity-A Supplement to Mental Health: A Report of the Surgeon General. Rockville, MD: U.S. Department of Health and Human Services, Substance Abuse and Mental Health Services Administration, Center for Mental Health Services.

Walker RD, Bigelow DA (2011). A constructive Indian country response to the evidence-based program mandate. Journal of Psychoactive Drugs 43, 276-281.

Whitley R (2014). Beyond critique: rethinking roles for the anthropology of mental health. Culture, Medicine, and Psychiatry 38, 499-511.

Whitley R (2015). Global mental health: concepts, conflicts and controversies. Epidemiology and Psychiatric Sciences, this issue. 